\title{
CORRESPONDENCE
}

\section{Liberties with energy}

SIR,-Gerald Leach (Nature, 21 February, page 714), suggests that the pursuit of a high conservation/low energy strategy would not touch personal liberties. No doubt this can be so, but if this policy is maintained it is difficult to believe that a really major effect on fuel conservation is likely to be achieved. There have been many cases in industry in which fuel conservation has actually been of financial advantage to the firms concerned, but it seems likely that the proportion of firms for which this is true will decrease as time goes on, and that many firms will find the value marginal if not negative.

In a depressed and highly competitive period it is very unlikeiy that firms will at all readily undertake extra expenditure which is not immediately productive, and firms exerting freedom of choice are likely to stay as they are. The likelihood therefore that we shall do too little too late on a voluntary basis is really quite large, in which case Gerald Leach himself says that energy conservation may have to be forced through by controls on individuals.

I am not myself too much bothered by this. The interference with civil liberties would be little more than the controls exerted by fire, smoke control and town-planning regulations. At the same time, I can see no reason to suppose that any protection of nuclear installations that may be necessary should have a worse effect on civil liberties than the similarly necessary protection of many industrial activities such as chlorine production or the manufacture of nylon precursors at Flixborough. Freedom to walk into other people's factories does not come high on my list of vital freedoms, whether they are processing nuclear wastes or military weapons or indeed cigarettes. A severe shortage of power with strict rationing would seem to me a more serious limitation of my liberties than would the fact that I could not get into a nuclear processing works without passing somebody carrying a revolver.

If there is a genuine risk of a terrorist attempt to kill many thousands of people in a single major incident, we should have to introduce a great many controls much more onerous than the guarding of a few well defined nuclear establishments in limited areas. One would, for example, need to control an appreciable area of South Essex and North Kent to ensure that a few saboteurs with a rocket launcher should not blow up the Canvey Island stores of liquified natural gas some dark night with a westerly breeze. Yours faithfully,

Department of Physics,

University of Birmingham

\section{CEGB on radiation}

SIR,-Further to the item headed 'UK Radiation Study Overestimates Safety' (14 February, page 614). I wish to point out that the radiation dose data supplied by the Central Electricity Generating Board to the Health and Safety Executive and also published elsewhere does include the doses received by workers other than those directly employed by the CEGB. We consider it important to include the radiation doses of al classified workers in the dose data relevant to the operation of CEGB nuclear power stations. Only by using such data can sensible comparisons be made between the doses received at nuclear power stations in the UK and those in other countries.

You may be interested to know that the total dose received by non-CEGB classified persons at all CEGB nuclear power stations in
1978 was 236 man-rems, and that received by CEGB personnel was 1399 man-rems. The mean dose per man for each category was 168 mrem and 257 mrem respectively. Yours faithfully,

Health and Safety Department, CEGB, London, UK

\section{Lost in translation?}

SiR, - Your readers may know that Nobel Prize lectures are translated into many languages. Mine, delivered in 1977, described the growth of our understanding of noncrystalline semiconductors and contains the following sentence. "The discovery of this property of glasses" (namely that they cannot be doped) "certainly makes Kolomiets"

(Leningrad) "one of the fathers of the branch of science that I am describing, as were others in Eastern European countries, notably Grigorovici in Bucarest and Tauc in Prague." Grigorovici remains in Bucarest, I believe retired; Tauc is in America.

For reasons unknown to me, the translated version published by the Czechoslovak

Journal of Physics, with the permission of the Nobel Foundation, omits the last two of these names. A letter to the editor-in-chief from the Nobel Foundation, dated 7 November 1979 and asking for an explanation has not yet been answered.

\section{Department of Physics, University of Cambridge, UK}

\section{Insignificant figures}

SIR, - Uncritical recording of estimations with numbers that include insignificant figures is a plague in scientific literature. Although technological advancements make possible increasingly more accurate measurements, overall precision is limited by the less accurate step involved. Moreover, modern calculators tend to increase the number of figures without any relation to significance.

To quantify this abuse we have examined a selection of first class journals looking for clearly insignificant figures. The results exceeded our expectations: in the issue(s) corresponding to one month of 1979 all journals examined had several papers with insignificant figures. The journals are: Eur. $J$. Biochem., J. Biol. Chem., Nature, Proc. Natl. Acad. Sci. USA, and Science. For illustration, five examples taken from the above sampling are listed below (followed by appropriately rounded numbers in brackets):

enzyme activity: $913,856 \mathrm{U}\left(914 \times 10^{3} \mathrm{U}\right)$

enzyme activation: $1005 \pm 80 \%$ of control (10 fold activation \pm 1 )

glycogen in muscle: $22.43 \pm 2.89 \mu \mathrm{mol} / \mathrm{g}$

$(22.4 \pm 2.9 \mu \mathrm{mol} / \mathrm{g})$

one type of cell in mice spleen:

$104,662 \pm 18,937\left(105 \times 10^{3} \pm 19 \times 10^{3}\right)$

weight of fed female ticks: $297.26( \pm 63.6) \mathrm{mg}$

(297 ( \pm 64$) \mathrm{mg}$ )

From extrapolation of this small sample it seems that over $10 \%$ of currently published scientific papers contain insignificant figures.

To obtain useful information from these multifigured numbers the reader has to do some mental operations (even if largely unconsciously), to eliminate from consideration the irrelevant figures, keeping three at the most. Would it not be much better to weed out the inordinately large numbers once and for all from (computer) calculation to publication? Insignificance usually runs parallel to irrelevance. Results should be both analytically significant and scientifically relevant; everything else would be noise. For instance, the liver of a young rat may weigh in a balance as $6.2345 \mathrm{~g}$; but because of the uncertainties on how much is really "the liver" (vascular pedicle, blood, and other factors), only $6.23 \mathrm{~g}$ would be relevant in most cases. Four or more figures would generally be mere pseudoprecision, even if analytically significant.

The rampant pseudoprecision of most results given with 4 to 6 figures must be stopped. It is suggested that authors should carefully consider the significance of the results so that only the last given figure is tentative. This practice will usually limit, in the presentation of results, the number of figures to 3 , and in many cases to 2 or even 1 . Obviously this norm does not apply in the case of serial numbers, dates, etc. For arithmetic means, with non-negative data, if the coefficient of variation $(\sigma / \mathrm{m} \times 100)$ is greater than 5 , the mean should be expressed with the same number of significant figures as the individual data, since such a dispersion does not justify, in general, a greater precision. Only if it is smaller than 5, an additional significant figure could be appropriate. Exponential forms (i.e. $914 \times 10^{3}$ ) will aid and simplify in most cases the final presentation of results with a number of figures limited to the significant ones.

Finally we propose to the editors of scientific journals to include in the instruction to authors a statement that manuscripts with obviously insignificant figures would not be accepted, perhaps adding that manuscripts with results with more than 3 figures should have an explicit (and acceptable) justification in the text or in the accompanying letter to the editor. Scientific objectivity would benefit, and the work of the scientists would be easier. Implicitly, this policy would recognise the fact that some scientists spend months or even years improving conditions to add one significant figure to a constant. Moreover, scientific publishing would be a little less expensive, nowadays a not insignificant consideration.

Yours faithfully,

Alberto SOlS JosÉ LUIS CARRASCO Autonomous University of Madrid, Spain

\section{Exhibitionism}

SIR,- Your correspondent Jim Ritter, in an otherwise perceptive feature (3 January, page 6) on the proposed French science museum at La Villette, displays his ignorance of what contemporary museums have been doing during the last two decades. Far from being sources of magical effects - 'black boxes with pushbuttons' - they have developed a vast array of exhibits and programmes that make science more understandable and accessible to public visitors. Modern science museums demystify science and technology and suggest that, although complex, science can be understood, controlled, and even enjoyed.

The Association of Science-Technology Centers, to which more than 100 museums belong, would be glad to provide an itinerary of museum travels on several continents to bring him up to date.

I would recommend a tour through the tactile gallery and the visual perception exhibits of the Exploratorium (San Francisco), the human reproduction and sexuality exhibit at the Ontario Science Centre (Toronto), the plumbing exhibit and the Food for Life exhibit at the Museum of Science and Industry (Chicago), or the exhibition It's About time at the Franklin Institute (Philadelphia). Your faithfully,

Michael TempletoN

Association of Science-Technology Centers, Washington DC, US 